\title{
Panax ginseng Total Protein Facilitates Recovery from Dexamethasone-Induced Muscle Atrophy through the Activation of Glucose Consumption in C2C12 Myotubes
}

\author{
Rui Jiang, ${ }^{1}$ Manying Wang, ${ }^{2}$ Lei Shi, ${ }^{1}$ Jingyuan Zhou, ${ }^{1}$ Rui Ma, ${ }^{1}$ Kai Feng, ${ }^{1}$ Xuenan Chen, \\ Xiaohao Xu, ${ }^{2}$ Xiangyan Li, ${ }^{2}$ Tong $\mathrm{Li}\left(\mathbb{D},{ }^{3}\right.$ and Liwei Sun ${ }^{2}{ }^{2}$ \\ ${ }^{1}$ Jilin Technology Innovation Center for Chinese Medicine Biotechnology, College of Science, Beihua University, Jilin 132013, China \\ ${ }^{2}$ Research Center of Traditional Chinese Medicine, The Affiliated Hospital to Changchun University of Chinese Medicine, \\ Changchun, Jilin 130021, China \\ ${ }^{3}$ Departments of Pathology, The Johns Hopkins University School of Medicine, Baltimore, Maryland 21205, USA
}

Correspondence should be addressed to Tong Li; tli1@jhmi.edu and Liwei Sun; sunnylilwei@163.com

Received 20 February 2019; Revised 11 June 2019; Accepted 16 July 2019; Published 6 August 2019

Academic Editor: Adair Santos

Copyright (C) 2019 Rui Jiang et al. This is an open access article distributed under the Creative Commons Attribution License, which permits unrestricted use, distribution, and reproduction in any medium, provided the original work is properly cited.

\begin{abstract}
Background. The clinical anti-inflammatory drug dexamethasone (DEX) can cause many side effects such as muscle atrophy for long-term use. Muscle atrophy induced by DEX may be caused by decrease of glucose consumption. Panax ginseng C.A. Meyer was previously considered to be an antiatrophic agent for glucocorticoid- (GC-) treated therapies. As one of the main components, it remains unclear whether ginseng total protein (GP) facilitates recovery from muscle atrophy induced by DEX. Methods. In this study, GP was extracted and purified with Sephadex-G50. C2C12 myoblasts was induced with 2\% horse serum to differentiate into $\mathrm{C} 2 \mathrm{C} 12$ myotubes. Cell viability was analyzed by the MTT assay, and $\mathrm{Ca}^{2+}$ concentration was analyzed by a flow cytometer. The release of lactic dehydrogenase (LDH) and the glucose consumption were analyzed by spectrophotometry. The phosphorylation of AMP-activated protein kinase (AMPK), phosphoinositide 3-kinase (PI3K), and protein kinase B (Akt) and the expression of glucose transporter 4 (GLUT4) were analyzed by Western blotting. The phosphorylation of AS160 was quantified by Immunofluorescence staining. Results. We found that GP increased cell viability and increased myotube diameter in high-dose DEX-treated C2C12 myotubes for $24 \mathrm{~h}$, but this activity was not found in the enzymatic hydrolyzed GP group. GP reduced muscle atrophy by decreasing the expression of key proteins such as muscle RING-finger protein-1 and muscle atrophy F-box, reducing the $\mathrm{Ca}^{2+}$ concentration, and decreasing the release of LDH in DEX-injured C2C12 myotubes. Moreover, GP improved glucose consumption and increased the phosphorylation of AMPK, PI3K, Akt, and AS160 and the expression of GLUT4 in DEX-treated C2C12 myotubes. Conclusion. The results of this study suggest that GP has effects on recovering DEX-induced muscle atrophy and cell injury, which may improve glucose consumption via the AMPK and PI3K/Akt pathways in high-dose DEX-treated C2C12 myotubes. This study provides in vitro mechanistic insights into the recovery of muscle atrophy with GP treatment.
\end{abstract}

\section{Introduction}

As a synthetic glucocorticoid (GC), dexamethasone (DEX) has anti-inflammatory [1], antiallergic [2], and antishock [3] properties. However, excess DEX leads to defects in glucose metabolism, muscle atrophy, and insulin resistance $[4,5]$. Muscle atrophy has profound effects on the daily life of patients, especially on physical activity, and decreases body movements to cause movement disorders and much inconvenience [6]. Therefore, improvement of muscle atrophy caused by DEX is of great significance for expanding its clinical application.

In skeletal muscle, it is well known that high-dose or prolonged GC treatment inhibits glucose consumption and utilization by antagonizing the insulin response, resulting in mitochondrial dysfunction and muscle atrophy [7, 8]. The promotion of glucose transport is mediated by $5^{\prime}$ monophosphate-activated protein kinase (AMPK) [9]. Activation of AMPK enhances the translocation of glucose transporter isoform 4 (GLUT4) to the cell membrane and then 
increases glucose consumption [10]. Glucose is transported through GLUT4 into skeletal muscle. In addition to involving the AMPK pathway, the insulin receptor-mediated PI3K/Akt pathway participates in regulating GLUT4 expression. The Akt substrate designated AS160 (160 kDa) is a Rab GTPaseactivating protein that modulates GLUT4 trafficking in insulin-sensitive L6 myoblasts [11]. Muscle atrophy induced by DEX begins with a decrease in myotube diameter, which is reflected by both a decrease in synthesis and an increase in protein degradation [12]. This process is mainly caused by activating the ubiquitin-proteasome system, which is mediated by key proteins such as atrogin-1/muscle atrophy F-box and muscle RING finger 1 (MuRF 1) [13]. These are two muscle-specific E3 ubiquitin ligases that are expressed early in the muscle atrophy process; their expression precedes the loss of muscle mass.

Mouse skeletal muscle-derived $\mathrm{C} 2 \mathrm{C} 12$ myoblasts are immortal mouse skeletal myoblasts originally derived from satellite cells of the thigh muscle [14], and have been used in many studies as an in vitro cell atrophy model [15]. Many studies have showed that DEX treated on $\mathrm{C} 2 \mathrm{C} 12$ myotubes could show cell atrophy by inducing increased protein degradation and other metabolic changes, which seen in atrophying muscle in experimental animals [16]. Therefore, in vitro DEX-induced cell atrophy model is convenient and mature to clarify the effects and mechanisms of active ingredients from medicinal herbs.

Panax ginseng C.A. Meyer as a Traditional Chinese Medicine is widely used in clinical applications, as it has immunomodulatory activity in mice and rats [17], antihyperglycemic effects in $\mathrm{C} 2 \mathrm{C} 12$ myotubes and mice [18], analgesic effects, and suppresses oxidative stress in mice [3]. Ginseng has protective effects on muscle atrophy in rats [19]. Panaxatriol derived from ginseng has protective effects on skeletal muscle mass in diabetic mice [20]. Ginsenoside Rg1 prevents muscle protein degradation by regulating Akt/ mTOR/FoxO signaling in $\mathrm{C} 2 \mathrm{C} 12$ myotubes [21], and prevents myotube atrophy through activating the Akt/mTOR pathway [13]. Available evidence has suggested that ginseng plays a role in increasing glucose consumption, and may reduce muscle atrophy in the $\mathrm{db} / \mathrm{db}$ mice: a model for diabetic dyslipidemia [22]. However, it is unclear whether it can inhibit muscle atrophy by regulating the glucose consumption pathway. As a key ingredient of Panax ginseng C.A. Meyer, ginseng total protein (GP) has antifatigue activity in mice [23]. We hypothesized that GP may facilitate recovery of skeletal muscle mass after cell atrophy.

\section{Materials and Methods}

2.1. Materials. Mouse skeletal muscle-derived $\mathrm{C} 2 \mathrm{C} 12$ myoblasts (GNM26) were purchased from the Chinese Academy of Sciences (Shanghai, China). Fetal bovine serum (FBS) was purchased from Clark Bioscience (Richmond, VA, USA). Horse serum was purchased from GIBCO (Life Technologies, Carlsbad, CA, USA). DEX was purchased from Sigma (St. Louis, MO, USA). The lactic dehydrogenase (LDH) Biochemical Analysis Kit was purchased from Jiancheng Bioengineering Institute (Nanjing, China). Fluo-3/AM and the BCA Protein Assay Kit were purchased from Beyotime Biotechnology (Shanghai, China). Protease/phosphatase inhibitor cocktails were purchased from Roche (Basel, Switzerland). Primary antibodies against myogenin, MuRF 1, atrogin-1, phosphorylated AMPK (p-AMPK), AMPK, phosphorylated PI3K (p-PI3K), PI3K, phosphorylated Akt (p-Akt), Akt, GLUT4, and GAPDH were obtained from Cell Signaling Technology (Beverly, MA, USA). p-AS160 was obtained from OmnimABs (Alhambra, CA, USA). Chemiluminescence reagents were purchased from Santa Cruz Biotechnology (Santa Cruz, CA, USA).

2.2. Preparation of GP. Five-year-old ginseng roots were collected from Fusong in the Province of Jilin, China (latitude, 127.27; longitude, 42.33) in September 2016 and were identified by Jie $\mathrm{Wu}$, a ginseng expert of Jilin Province. The voucher specimen (2145) was conserved at the Herbarium of College of Science, Beihua University (Jilin province, China). GP was prepared by the same method in the published article of the same laboratory [24]. Fresh ginseng roots $(1 \mathrm{~kg})$ were cut into small slices and extracted twice with phosphatebuffered saline (PBS) at $4^{\circ} \mathrm{C}$ for $4 \mathrm{~h}$. The supernatant was condensed with an ultrafiltration membrane $(30 \mathrm{kDa})$ and the concentrated solution was separated with Sephadex G50, the purity of which reached $90.2 \%$. The filtrate was dried using a vacuum freeze dryer. GP purity was measured by a BCA Protein Assay Kit, and the molecular weight distribution was detected by sodium dodecyl sulfate polyacrylamide gel electrophoresis (SDS-PAGE). To further test the anti-atrophy effects of GP, we hydrolyzed GP with $50 \mu \mathrm{g} / \mathrm{mL}$ proteinase $\mathrm{K}$ for 10 or $30 \mathrm{~min}$, which were inactivated at $85^{\circ} \mathrm{C}$ for $1 \mathrm{~h}$.

2.3. Cell Culture and Differentiation. C2C12 myoblasts were cultivated in high-glucose Dulbecco's modified Eagle's medium (DMEM) containing $25 \mathrm{mM}$ glucose, 10\% FBS, 100 units/mL penicillin, and $100 \mu \mathrm{g} / \mathrm{mL}$ streptomycin and were incubated at $37^{\circ} \mathrm{C}$ in a water-saturated atmosphere of $5 \%$ $\mathrm{CO}_{2}$. When the myoblasts were $70-80 \%$ confluent, $\mathrm{C} 2 \mathrm{C} 12$ myoblasts $\left(7.5 \times 10^{4}\right.$ cells/well $)$ were seeded in a 6 -well and 5 $\times 10^{4}$ cells/well were seeded in a 96-well plate, and induced to fuse into $\mathrm{C} 2 \mathrm{C} 12$ myotubes using high-glucose DMEM containing $25 \mathrm{mM}$ glucose and $2 \%$ horse serum for 1 to 7 days [13]. We observed the cell morphology by Giemsa staining to delineate the differentiated cell status. Western blotting analysis was used to determine the level of myogenin, a marker of myogenic differentiation.

2.4. Treatment with DEX and GP. After $5 \mathrm{~d}$ of differentiation, C2C12 myotubes were subdivided into five groups: (1) the control group, in which cells were incubated for $24 \mathrm{~h}$ in medium; (2) the DEX group, in which cells were treated with $200 \mu \mathrm{M}$ DEX for $24 \mathrm{~h}$; and (3) the DEX + GP group, in which cells were treated with DEX plus GP $(5,10$, and $20 \mu \mathrm{g} / \mathrm{mL})$ for $24 \mathrm{~h}$. All groups were harvested for experiments.

2.5. Cell Viability Assay. Cell viability was assessed by the MTT assay [25]. Briefly, C2C12 myotubes $\left(5 \times 10^{4}\right.$ cells/well $)$ were seeded in 96-well plate for $24 \mathrm{~h}$, and treated with 
DEX and/or different concentrations of GP or bovine serum albumin (BSA) for $24 \mathrm{~h}$. After incubation with $0.5 \mathrm{mg} / \mathrm{mL}$ MTT for $4 \mathrm{~h}$ at $37^{\circ} \mathrm{C}, 150 \mu \mathrm{L}$ dimethyl sulfoxide (DMSO) was added to the cells and absorbance was measured at 490 $\mathrm{nm}$. Cell viability was expressed as a percentage relative to the untreated control cells or DEX-treated cells.

2.6. Measurement of Myotube Diameters. To evaluate the effects of GP on the atrophy of $\mathrm{C} 2 \mathrm{C} 12$ myotubes induced by DEX, the cell diameters were measured according to a previously described method with some modifications [15]. Briefly, C2C12 myoblasts $\left(5 \times 10^{4}\right.$ cells/well) were seeded in 96-well plates for $24 \mathrm{~h}$ and then treated with DEX and/or different concentrations of GP $(5,10,20 \mu \mathrm{g} / \mathrm{mL})$ for $24 \mathrm{~h}$. Myotubes were fixed in $4 \%$ paraformaldehyde for $10 \mathrm{~min}$ before being stained with $10 \%$ Giemsa, and observed by light microscopy. The diameters of $\mathrm{C} 2 \mathrm{C} 12$ myotubes were calculated $(n=200)$ using Gen 5 data analysis software (BioTek, Winooski, VT, USA).

2.7. Lactate Dehydrogenase ( $L D H)$ Assays. To understand the effects of GP on the extent of cell injury induced by DEX, the release of $\mathrm{LDH}$ in the culture supernatant was measured using the LDH Biochemical Analysis Kit. After treatment with GP, $200 \mu \mathrm{L}$ culture medium from C2C12 myotubes with DEX and/or GP treatment for $24 \mathrm{~h}$ was used to examine LDH release by a microplate reader at $450 \mathrm{~nm}$ [26].

2.8. Measurements of Calcium $\left(\mathrm{Ca}^{2+}\right)$ Levels. According to the manufacturer's instructions with some modifications [27], the levels of $\mathrm{Ca}^{2+}$ in $\mathrm{C} 2 \mathrm{C} 12$ myotubes treated with DEX and/or GP were detected with the Fluo-3/AM calcium indicator. $\mathrm{C} 2 \mathrm{C} 12$ myotubes were dissolved in PBS containing $2 \mathrm{mM}$ Fluo 3-AM, and incubated for $30-60 \mathrm{~min}$ at $37^{\circ} \mathrm{C}$, during which time the Fluo 3-AM was trapped inside the cells by esterase cleavage. Then $\mathrm{Ca}^{2+}$ levels were measured by a flow cytometer (BD Biosciences, San Jose, CA, USA).

2.9. Glucose Consumption Assay. The glucose consumption assay was performed according to the method of Choi et al. [28]. Briefly, after differentiation, the $\mathrm{C} 2 \mathrm{C} 12$ myotubes were cultivated overnight and then treated with DEX and/or GP for $24 \mathrm{~h}$. After treatment, the glucose concentration in medium was measured with the sulfuric acid-phenol method. The amount of glucose consumed was calculated by measuring the glucose concentration in cell-plated wells from that in blank wells.

2.10. Western Blotting Analysis. Western blotting analysis was performed according to the method of Wang et al. [29, 30]. Cells were washed twice with ice-cold PBS, and lysed with RIPA lysis buffer containing protease/phosphatase inhibitor cocktails for $30 \mathrm{~min}$ on ice. Equal amounts of protein (30 $\mu \mathrm{g}$ ) were loaded and separated on $12 \%$ SDS-PAGE gels. After blocking in 5\% non-fat milk, membranes were incubated with primary antibodies overnight at $4^{\circ} \mathrm{C}$ and with horseradish peroxidase-conjugated secondary antibodies for $1 \mathrm{~h}$, after which proteins were visualized using chemiluminescence reagents and the FluorChem HD2 system.
2.11. Immunofluorescence Staining. $\mathrm{C} 2 \mathrm{C} 12$ cells were fixed in $4 \%$ formaldehyde for $15 \mathrm{~min}$, permeabilized with $0.1 \%$ Triton X-100, and incubated with phosphorylated AS160 (pAS160, Thr642) antibodies in microscopy buffer, followed by incubation with fluorescein isothiocyanate-conjugated secondary antibodies. The nucleus was stained with DAPI. Image acquisition and postprocessing were performed with a cell imaging multifunctional test system Cytation 5 (BioTek).

2.12. Statistical Analysis. Ordinary one-way ANOVA of variance was used to test differences among the groups. Data are presented as the mean \pm SD. GraphPad Prism 7.0 software was applied to all statistical analyses.

\section{Results}

3.1. GP Increases Cell Viability of C2C12 Myotubes Injured by DEX. After treatment with different doses of $\mathrm{GP}(2.5,5$, 10,20 , and $40 \mu \mathrm{g} / \mathrm{mL}$ ) for 24 and $48 \mathrm{~h}$, it was shown to have no effect on the viability of $\mathrm{C} 2 \mathrm{C} 12$ myotubes ( $24 \mathrm{~h}$ : $\mathrm{F}=3.11 ; 48 \mathrm{~h}: \mathrm{F}=11.28$, all $\mathrm{p}>0.05$; Figure $1(\mathrm{a}))$. Based on the muscle-impairing effects of DEX, the effects of GP on skeletal muscle cells injury were assessed. As shown in Figure 1(b), DEX decreased the viability of $\mathrm{C} 2 \mathrm{C} 12$ myotubes to $68.61 \pm$ $1.01 \%$, and GP recovered the cell viability of injured $\mathrm{C} 2 \mathrm{C} 12$ myotubes induced by DEX in a dose-dependent manner $(\mathrm{F}=13.67, \mathrm{p}<0.05)$. To determine if all proteins had this effect, we used BSA for functional research analysis, but BSA did not have this effect $(\mathrm{F}=19.95$, all $\mathrm{p}>0.05$, Figure $1(\mathrm{c}))$, suggesting that not all proteins can increase the cell viability of C2C12 myotubes injured by DEX. To confirm that GP was active, we subjected it to enzymatic hydrolysis. As shown in Figure 1(d), the main molecular weight of GP ranged from 16 to $68 \mathrm{kDa}$, with the major band present at $22 \mathrm{kDa}$; this band disappeared after enzymatic hydrolysis with $50 \mu \mathrm{g} / \mathrm{mL}$ proteinase $\mathrm{K}$ for $30 \mathrm{~min}$. We also did not find any influence of GP hydrolysate on the viability of $\mathrm{C} 2 \mathrm{C} 12$ myotubes $(\mathrm{F}=32.85$, all $\mathrm{p}>0.05$; Figure $1(\mathrm{e})$ ). These results indicated that the effects of promoting $\mathrm{C} 2 \mathrm{C} 12$ cell viability were attributed to $\mathrm{GP}$, and that GP reversed DEX-induced injury in muscle myotubes.

3.2. GP Decreases DEX-Induced $L D H$ Release and $\mathrm{Ca}^{2+}$ Concentration Increase in C2C12 Myotubes. In this study, the injury of $\mathrm{C} 2 \mathrm{C} 12$ myotubes induced by DEX was assessed by measuring $\mathrm{LDH}$ release in the culture medium. Compared to control cells, DEX led to a 2.24-fold increase of $\mathrm{LDH}$ release, whereas treatment with GP significantly decreased $\mathrm{LDH}$ release in DEX-induced $\mathrm{C} 2 \mathrm{C} 12$ myotubes in a dosedependent manner $(\mathrm{F}=15.81$, all $\mathrm{p}<0.05$, Figure $2(\mathrm{a}))$. Our results showed that the level of intracellular $\mathrm{Ca}^{2+}$ was increased up to 2.31-fold with DEX treatment compared to the control. Treatment with 5, 10, and $20 \mu \mathrm{g} / \mathrm{mL}$ GP reduced the concentration of $\mathrm{Ca}^{2+}$ by 1.43-, 1.29-, and 0.93-fold, respectively $(F=40.65$, all $p<0.05$, Figure $2(\mathrm{c}))$. These data showed that GP reduced the release of $\mathrm{LDH}$ and the concentration of $\mathrm{Ca}^{2+}$ induced by DEX in skeletal muscle myotubes.

3.3. GP Reduces DEX-Induced C2C12 Myotube Atrophy. To analyze the effects of GP on the protection of DEX-induced atrophy in myotubes, we first examined myotube diameter. 


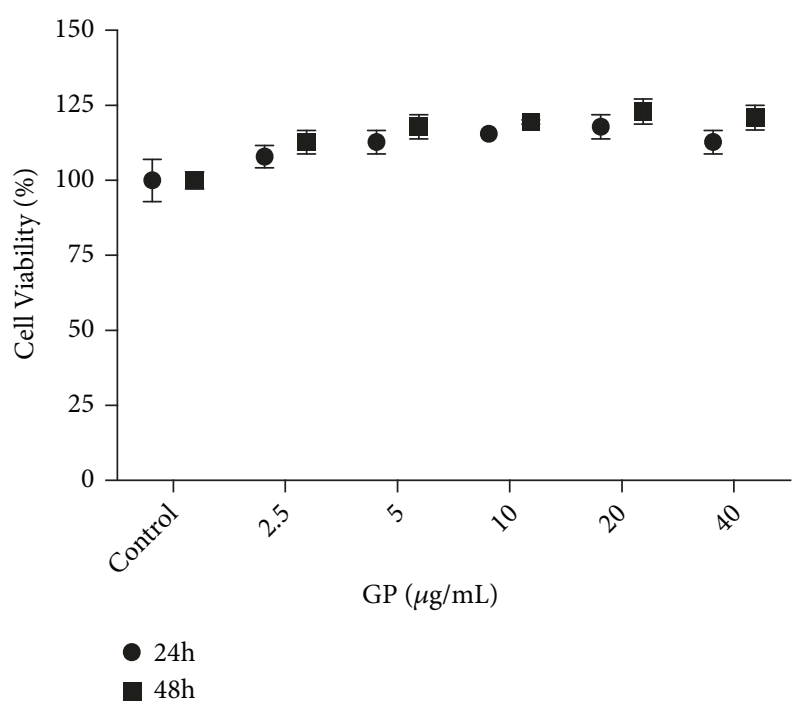

(a)

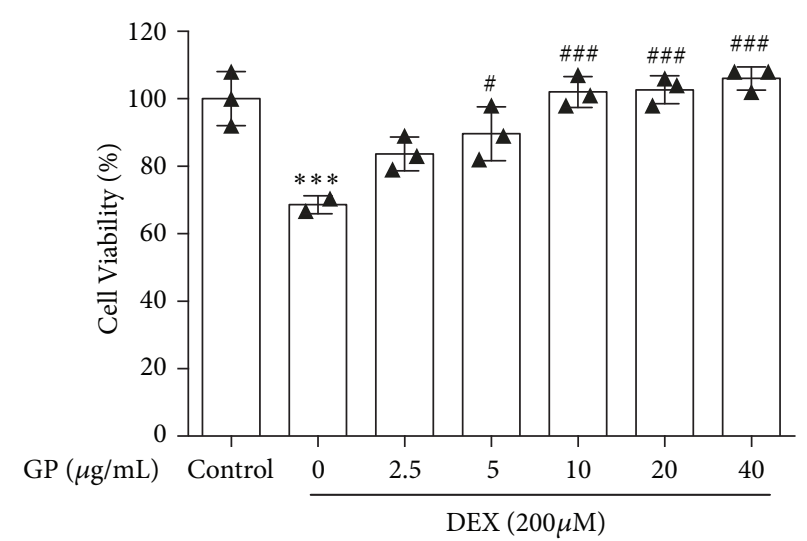

(b)

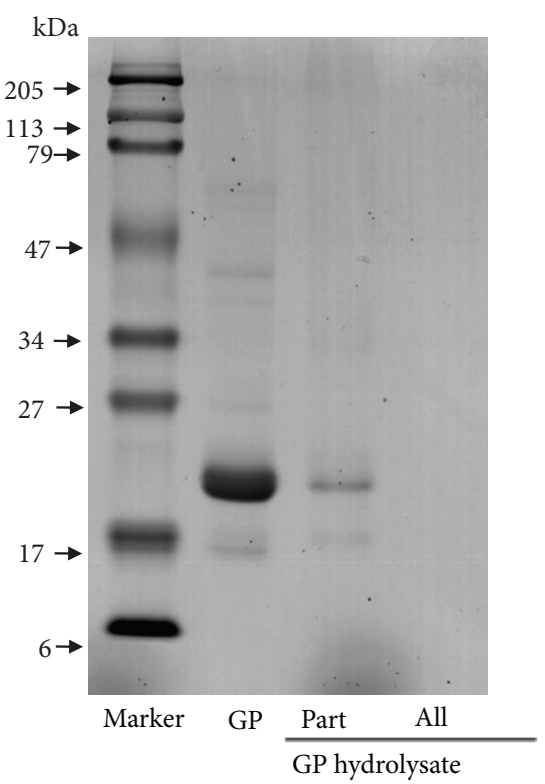

(d)

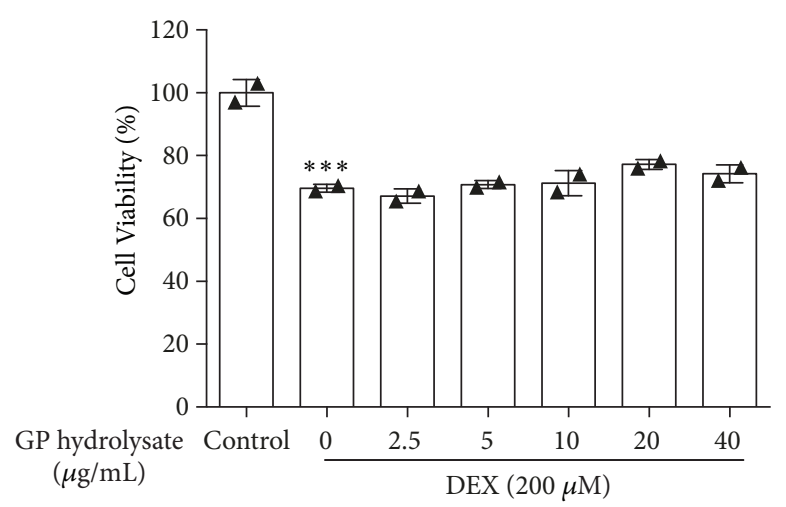

(e)

FIGURE 1: GP increases cell viability induced by DEX in C2C12 myotubes. (a) The MTT assay was used to analyze the cytotoxicity of GP $(2.5-40 \mu \mathrm{g} / \mathrm{mL})$ in C2C12 myotubes after treatment for 24 and $48 \mathrm{~h}$. (b) C2C12 myotubes were treated with GP $(2.5-40 \mu \mathrm{g} / \mathrm{mL})$ for $24 \mathrm{~h}$ after incubation with DEX for $24 \mathrm{~h}$. The viability of $\mathrm{C} 2 \mathrm{C} 12$ myotubes was assessed by the MTT assay. (c) C2C12 myotubes were treated with BSA $(2.5-40 \mu \mathrm{g} / \mathrm{mL}$ ) for $24 \mathrm{~h}$ after incubation with DEX for $24 \mathrm{~h}$. The viability of C2C12 myotubes was assessed by the MTT assay. (d) SDS-PAGE analysis of GP and GP hydrolysate. (e) C2C12 myotubes were treated with GP hydrolysate $(2.5-40 \mu \mathrm{g} / \mathrm{mL})$ for $24 \mathrm{~h}$ after incubation with DEX for $24 \mathrm{~h}$. The viability of C2C12 myotubes was assessed by the MTT assay. Data are expressed as the mean $\pm \mathrm{SD}(\mathrm{n}=3) ;{ }^{* *} p<0.01$ and ${ }^{* * *} p<$ 0.001 compared to the control group; ${ }^{\#} p<0.05$ and ${ }^{\# \#} p<0.001$ compared to the DEX group. 


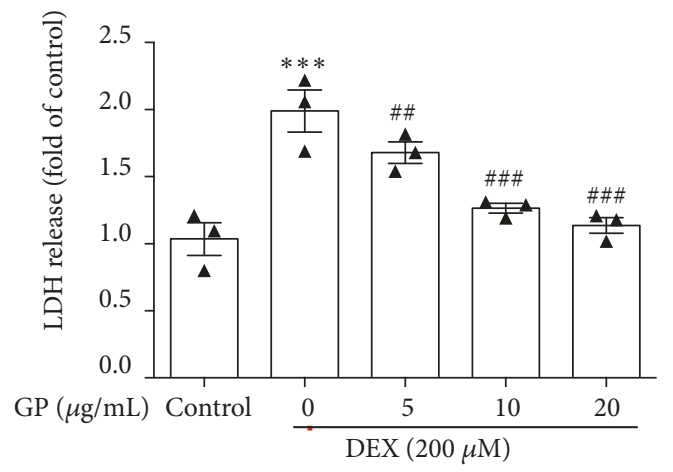

(a)
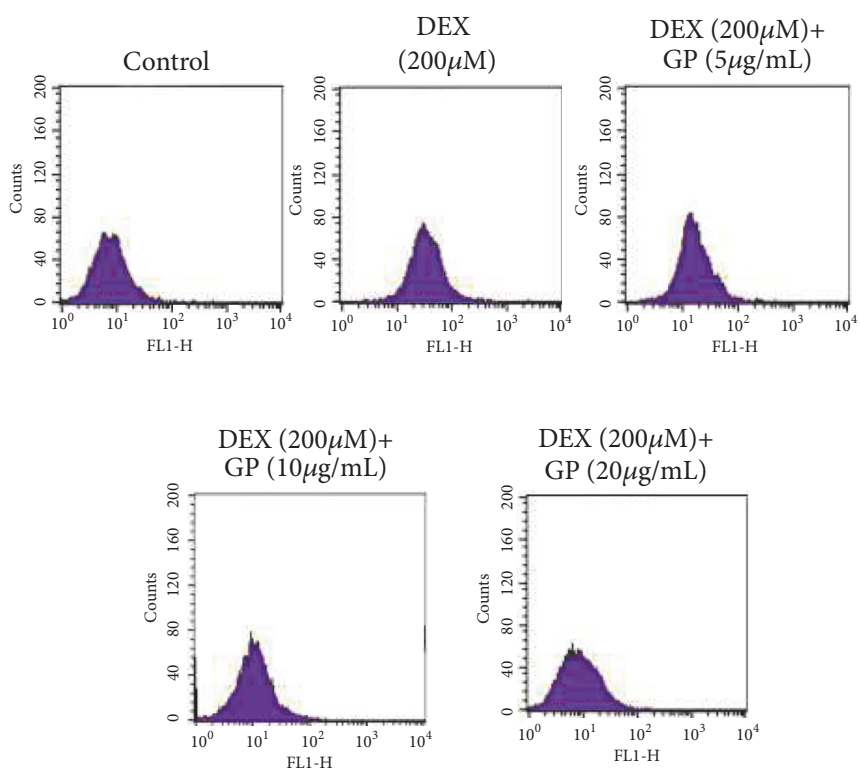

(b)

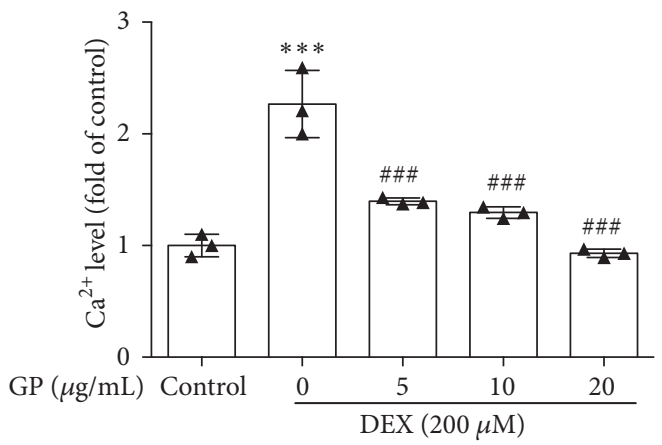

(c)

FIGURE 2: GP decreases DEX-induced LDH release and $\mathrm{Ca}^{2+}$ concentration increase in C2C12 myotubes. (a) After treatment with DEX for $24 \mathrm{~h}$, cells were incubated with GP $(5-20 \mu \mathrm{g} / \mathrm{mL})$ for $24 \mathrm{~h}$. LDH release was measured by spectrophotometry. (b) After treatment with DEX for $24 \mathrm{~h}$, cells were incubated with GP $(5-20 \mu \mathrm{g} / \mathrm{mL})$ for $24 \mathrm{~h} . \mathrm{Ca}^{2+}$ concentration was measured by flow cytometry. (c) Histogram analysis of $\mathrm{Ca}^{2+}$ concentration. Data are expressed as the mean $\pm \mathrm{SD}(\mathrm{n}=3) ;{ }^{* * *} p<0.001$ compared to the control group; ${ }^{\# \#} p<0.01$ and ${ }^{\# \# \#} p<0.001$ compared to the DEX group.

Figures 3(a) and 3(b) shows representative photos of $\mathrm{C} 2 \mathrm{C} 12$ myotubes taken immediately after completion of the experiment. Compared to the control group $(22.81 \pm 0.55 \mu \mathrm{m})$, the myotube diameter was significantly decreased upon exposure to $200 \mu \mathrm{M}$ DEX for $24 \mathrm{~h}(\mathrm{~F}=13.24, \mathrm{p}<0.001,14.74 \pm 0.48$ $\mu \mathrm{m})$. The myotube size increased after treatment with GP $(\mathrm{F}=13.24, \mathrm{p}<0.001,22.92 \pm 0.58 \mu \mathrm{m})$, whereas GP hydrolysate did not increase myotube size $(\mathrm{F}=13.24, \mathrm{p}>0.05,15.92 \pm 0.58$ $\mu \mathrm{m})$. These results indicate that GP plays a role in inhibiting cell atrophy caused by DEX. To further analyze the effects of GP on skeletal muscle cell atrophy, we examined the expression of MuRF 1 and atrogin-1, major atrophy-related E3 ubiquitin ligases specifically expressed in striated muscle. We found that DEX increased the expression of MuRF1 $(F=30.82$, all $\mathrm{p}<0.05$, Figure $3(\mathrm{~d}))$ and atrogin $-1(\mathrm{~F}=28.23$, all $\mathrm{p}<0.05$, Figure $3(\mathrm{e})$ ) in myotubes. These results showed that GP treatment decreased the expression of MuRF1 and atrogin-1 in DEX-treated myotubes.

3.4. GP Increases Glucose Consumption via the AMPK and PI3K/Akt Pathways in DEX-Induced C2C12 Myotube Atrophy. As shown in Figure 4(a), GP had no effects on glucose consumption of C2C12 myotubes ( $24 \mathrm{~h}: \mathrm{F}=1.729,48 \mathrm{~h}: \mathrm{F}=1.201$; all $\mathrm{p}>0.05)$. C2C12 myotubes treated with DEX decreased glucose consumption at a dose of $200 \mu \mathrm{M}$. DEX reduced glucose consumption by about $34.75 \pm 0.96 \%$ compared to the control (Figure 4(b)). Compared to the DEX-treated group, treatment with 5,10 , and $20 \mu \mathrm{g} / \mathrm{mL}$ GP increased glucose consumption by $19.27 \%, 32.27 \%$, and $29.93 \%$, respectively, $(\mathrm{F}=16.36$, all $\mathrm{p}<0.05$, Figure $4(\mathrm{c}))$, suggesting that GP increased glucose consumption in DEX-induced C2C12 


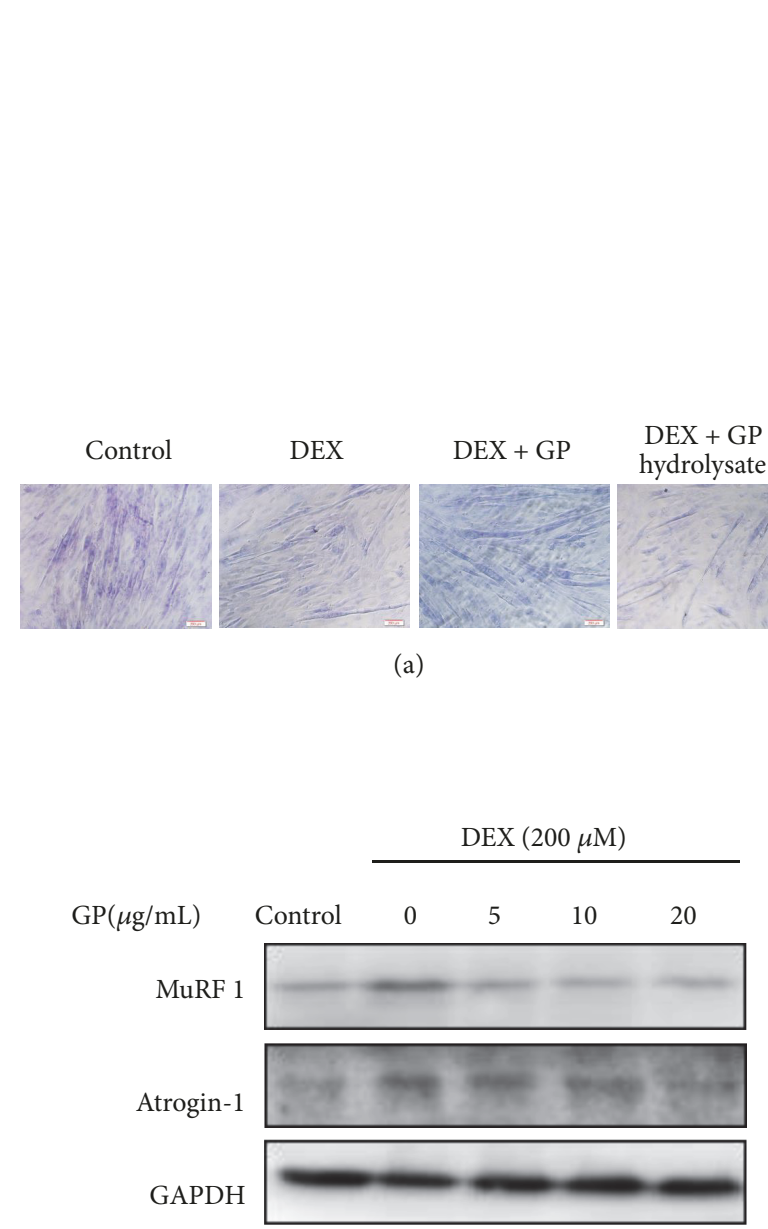

(c)

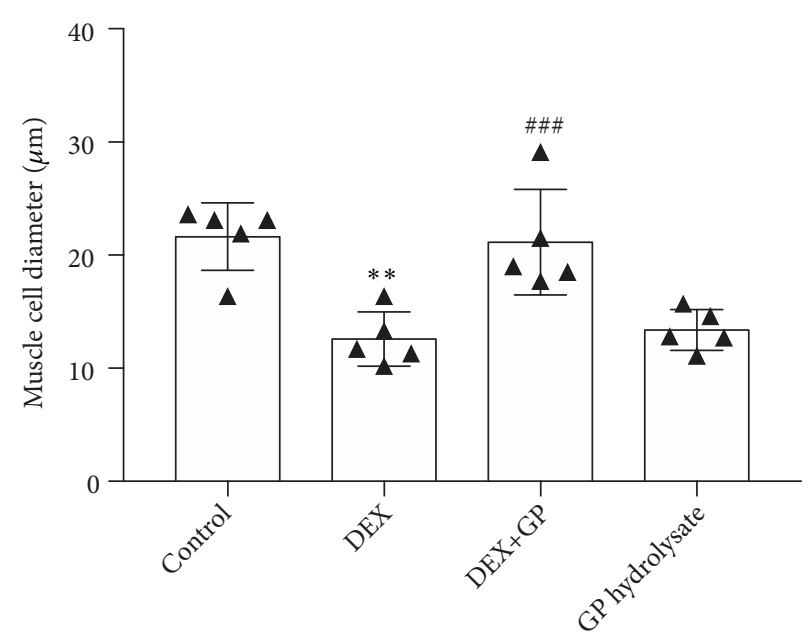

(b)

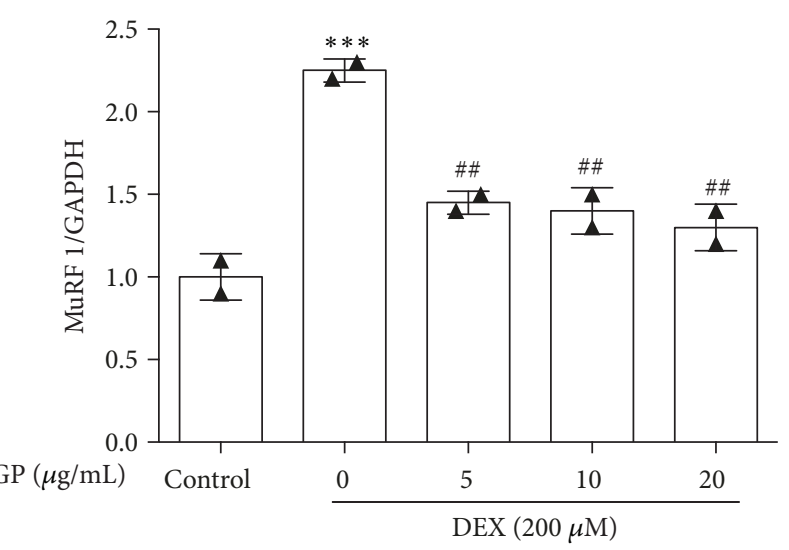

(d)

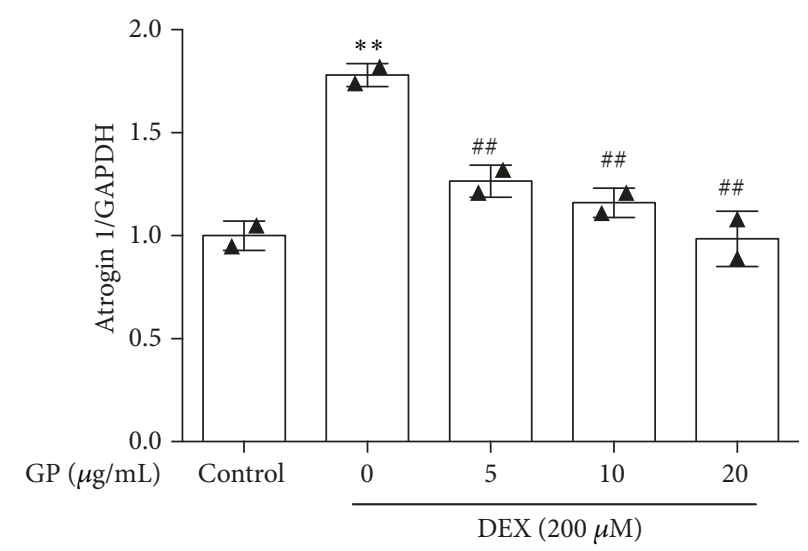

(e)

FIGURE 3: GP reduces DEX-induced C2C12 myotube atrophy. (a) Representative photographs of C2C12 myotubes for the control, DEX, DEX+GP hydrolysate treatments. (b) Comparison of the cell diameters among the four groups measured after completion of the experiments. (c) After treatment with GP for $24 \mathrm{~h}$, the levels of MuRF1 and atrogin1 in DEX-injured C2C12 myotubes were detected by Western blot analysis. (d) The relative expression of MuRF1 was quantified by densitometry analyses. (e) The relative expression of atrogin-1 was quantified by densitometry analyses. GAPDH was used as the loading control. Data are expressed as the mean $\pm \operatorname{SD}(\mathrm{n}=3) ;{ }^{* *} p<0.01$ and ${ }^{* * *} p<0.001$ compared to the control group; ${ }^{\# \#} p<0.01$ and ${ }^{\# \# \#} p<0.001$ compared to the DEX group. 


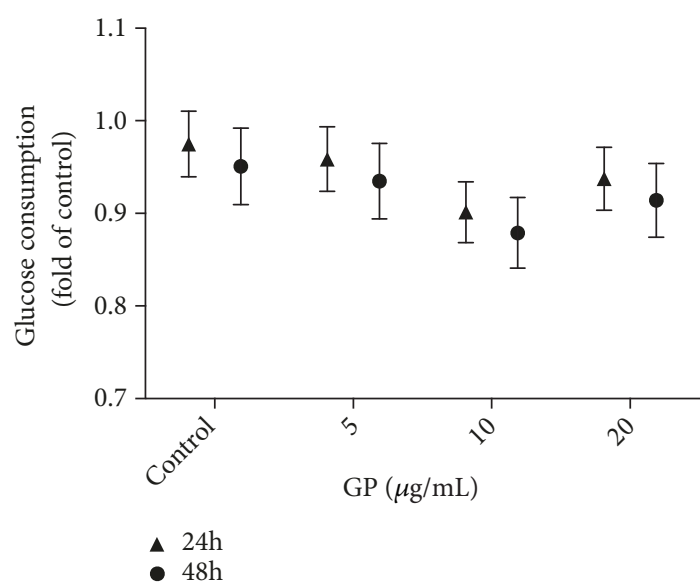

(a)

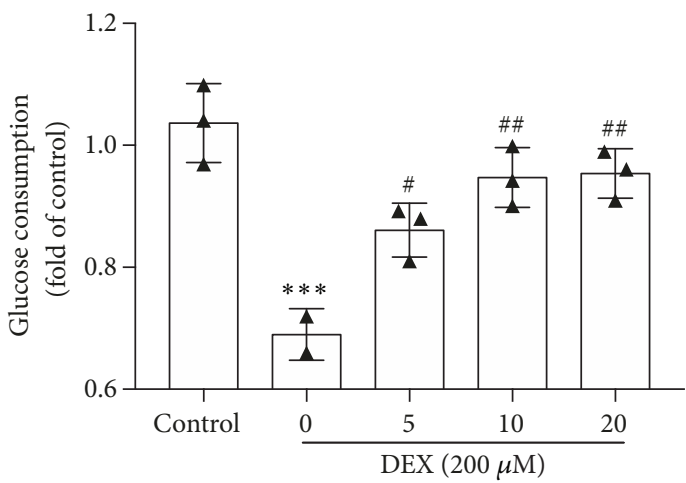

(c)

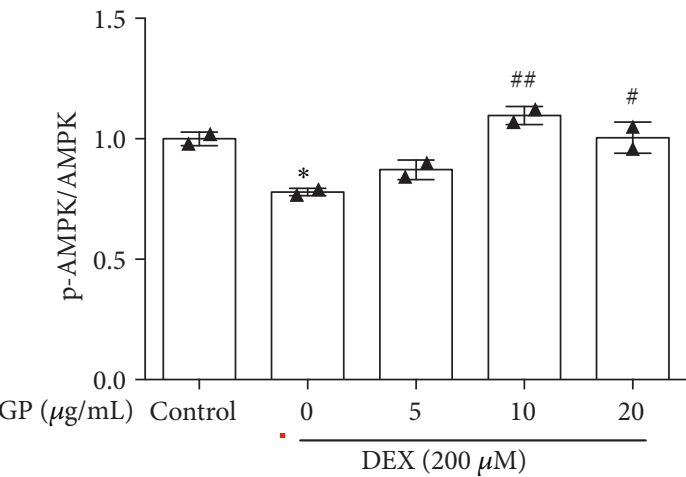

(e)

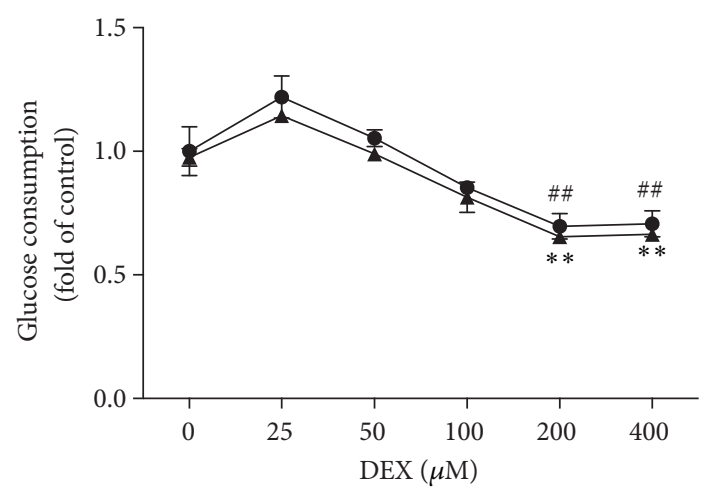

(b)

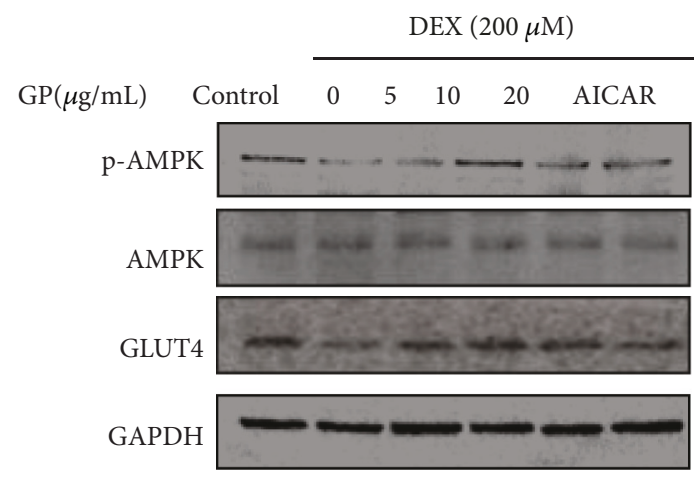

(d)

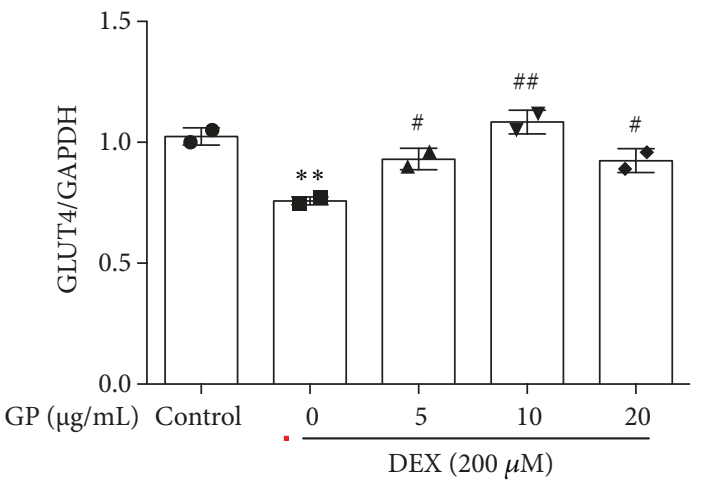

(f)

FIGURE 4: GP increases glucose consumption in DEX-induced C2C12 myotube atrophy by AMPK/GLUT4 pathway. (a) After treatment with GP for 24 and $48 \mathrm{~h}$, glucose uptake was measured by spectrophotometry. (b) After treatment with DEX for 24 and 48 h, glucose uptake was measured by spectrophotometry. ${ }^{* *} p<0.01$ versus $24 \mathrm{~h}$; ${ }^{\# \#} p<0.01 \mathrm{vs.} 48 \mathrm{~h}$. (c) After treatment with DEX for $24 \mathrm{~h}$, cells were incubated with GP $(5-20 \mu \mathrm{g} / \mathrm{mL})$ for $24 \mathrm{~h}$. Glucose uptake was measured by spectrophotometry. (d) After treatment of GP for $24 \mathrm{~h}$, the levels of p-AMPK/AMPK and GLUT4 in DEX-injured C2C12 myotubes were detected by Western blot analysis. (e) The relative expression of p-AMPK/AMPK was quantified by densitometry analyses. (f) The relative expression of GLUT4 was quantified by densitometry analyses. Data are expressed as the mean \pm SD $(\mathrm{n}=3) ;{ }^{*} p<0.05,{ }^{* *} p<0.01$, and ${ }^{* * *} p<0.001$ compared to the control group; ${ }^{\#} p<0.05$ and ${ }^{\# \#} p<0.01$ compared to the DEX group.

myotube atrophy. We found that DEX decreased the phosphorylation of AMPK and GLUT4 expression in myotubes. GP increased the phosphorylation of AMPK $(\mathrm{F}=20.31$, all $\mathrm{p}<0.05$; Figure $4(\mathrm{e}))$ and the expression of GLUT4 $(\mathrm{F}=18.58$, all $\mathrm{p}<0.05$; Figure $4(\mathrm{f})$ ) in DEX-induced C2C12 myotube atrophy, similar to the AMPK activator, AICAR [31]. We also found that DEX decreased the phosphorylation of PI3K and Akt in myotubes. GP restored the phosphorylation of PI3K $(\mathrm{F}=14.39$, all $\mathrm{p}<0.05$; Figure $5(\mathrm{~b}))$ and Akt $(\mathrm{F}=13.71$, all $\mathrm{p}<0.05$; Figure $5(\mathrm{c}))$ in DEX-induced $\mathrm{C} 2 \mathrm{C} 12$ myotube atrophy. In addition, DEX decreased the phosphorylation of AS160 in myotubes, while GP restored the phosphorylation of 


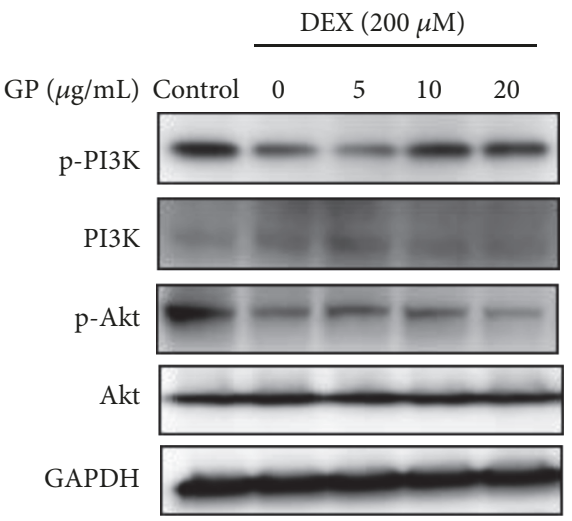

(a)

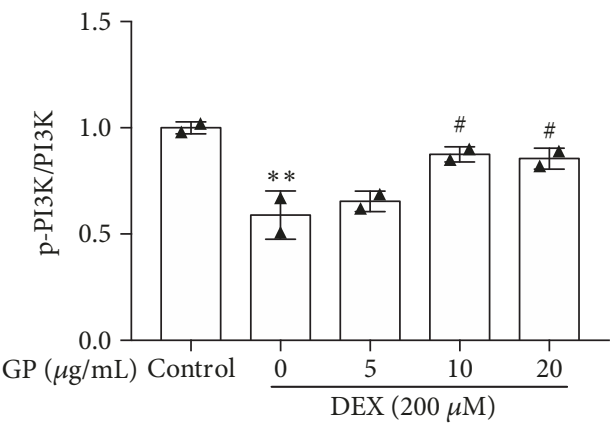

(b)

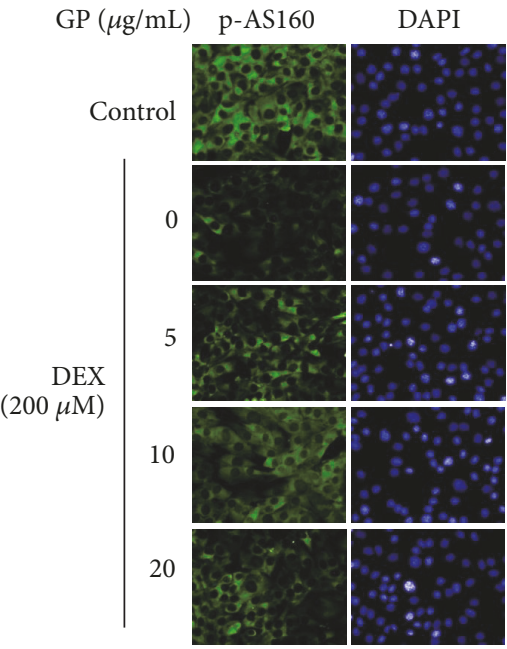

(d)

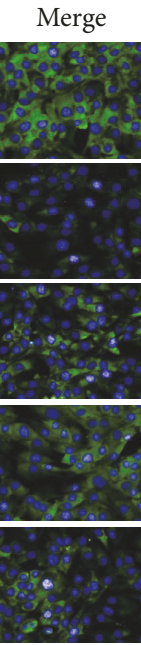

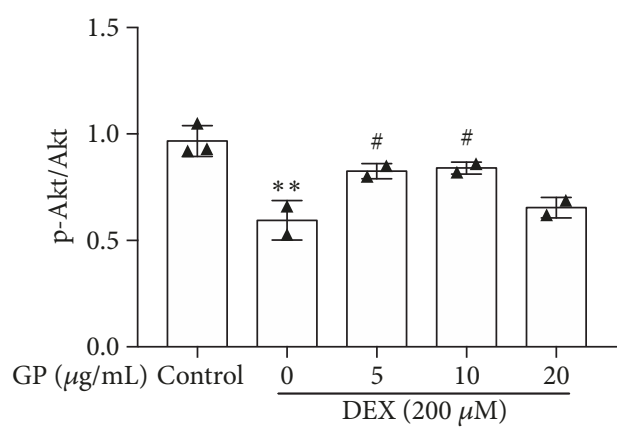

(c)

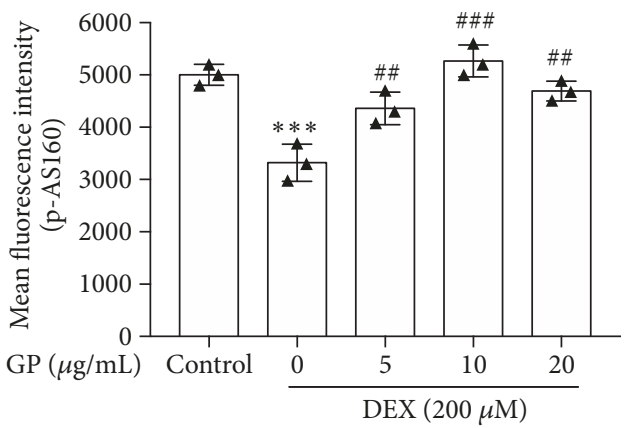

(e)

FIgURE 5: GP increases glucose consumption in DEX-induced C2C12 myotube atrophy by PI3K/Akt pathway. (a) After treatment with GP for $24 \mathrm{~h}$, the levels of p-PI3K/PI3K and p-Akt/Akt in DEX-injured C2C12 myotubes were detected by Western blot analysis. (b) The relative expression of p-PI3K/PI3K was quantified by densitometry analyses. (c) The relative expression of p-Akt/Akt was quantified by densitometry analyses. (d) The relative phosphorylation of AS160 was quantified by Immunofluorescence staining. (e) The relative phosphorylation of AS160 was quantified by densitometry analyses. Data are expressed as the mean $\pm \operatorname{SD}(\mathrm{n}=3) ;{ }^{* *} p<0.01$ and ${ }^{* * *} p<0.001$ compared to the control group; ${ }^{\#} p<0.05,{ }^{\# \#} p<0.01$, and ${ }^{\# \#} p<0.001$ compared to the DEX group.

AS160 in DEX-induced C2C12 myotube atrophy ( $\mathrm{F}=25.46$, all $\mathrm{p}<0.05$; Figure $5(\mathrm{e}))$. These results indicated that GP reduced DEX-induced $\mathrm{C} 2 \mathrm{C} 12$ myotube atrophy by enhancing the AMPK and PI3K/Akt pathways, which play a role in glucose consumption in skeletal muscle cells.

\section{Discussion}

GC has a wide range of clinical applications, but can cause many myopathies. High-dose synthetic GC DEX can induce muscle fibers to become thinner and decrease muscle mass. 
Muscle atrophy caused by DEX is caused by an increase in muscle protein degradation and a decrease of muscle protein synthesis. This phenomenon may occur by activating catabolic signals including ubiquitin E3 ligases MuRF1 and atrogin-1 [32]. Fructus Schisandrae [33], celastrol [15], ginsenoside Rb1 [21], and many Traditional Chinese Medicines [34] or extracts [35] have antiatrophy effects, even when used in the clinic. GP also had similar effects, and as such, has potential therapeutic applications. Our results showed that GP increased cell viability from DEX-induced cell injury and protected the injured cell membrane by decreasing the level of $\mathrm{LDH}$ release. GP had protective effects by increasing the release of $\mathrm{Ca}^{2+}$ accumulation to reduce injury from DEX in $\mathrm{C} 2 \mathrm{C} 12$ myotubes. Our results also showed that myotube size and the expression of MuRF 1 and atrogin-1 were increased after treatment with GP in DEX-treated myotubes. The results showed that GP inhibited $\mathrm{C} 2 \mathrm{C} 12$ myotube atrophy induced by DEX by regulating the expression of MuRF 1 and atrogin1. Muscle tissue is composed of many muscle fibers, and myotubes are basic units that make up the muscle fibers. Therefore, myotube atrophy recovery by GP may provide an experimental basis for using this protein to recover muscle atrophy in vivo.

Skeletal muscle is one of the major tissues responsible for glucose homeostasis, as about $80 \%$ of glucose utilization occurs in skeletal muscle [36]. Some evidence has shown that GCs have very complex effects on glucose consumption in various tissues and cells. It has also been shown that GCs can inhibit glucose consumption and induce muscle cell atrophy [15]. In accordance with these reports, we found that treatment with DEX decreased glucose consumption in $\mathrm{C} 2 \mathrm{C} 12$ myotubes, which was attenuated by GP. These results indicate that GP might partially protect $\mathrm{C} 2 \mathrm{C} 12$ myotubes against DEX-induced atrophy by improving the glucose consumption of these cells. Ginsenoside Rgl prevents myotube atrophy by activating the Akt/mTOR/FoxO target pathway [21]. Thus, GP can recover DEX-induced muscle atrophy by regulating glucose consumption, which differs from the reported pathway of Ginsenoside Rg1.

Glucose is transported through GLUT4 into skeletal muscle. In addition to the AMPK pathway, the insulin receptor-mediated PI3K/Akt pathway also participates in the regulation of GLUT4 expression [10, 37]. AMPK is a master sensor and regulator, which plays a role in cellular energy homeostasis and mediates the contraction-evoked promotion in glucose transportation [38]. Glucose is transported through GLUT4 into skeletal muscle. AS160 is a molecular link among diverse signaling cascades converging on GLUT4 translocation. The activation of PI3K/AKT results in phosphorylation of the Akt substrate AS160 to induce the cellular distribution of GLUT4. In turn, the activity of PI3K recruits the serine/threonine kinase Akt to the cell membrane. This feedback loop is thought to be critical for insulinmediated GLUT4 translocation from endosomal storage sites to the sarcolemma. Our results showed that GP led to a dose-dependent increase in the phosphorylation of AMPK, PI3K/Akt, and AS160 and increased GLUT4 expression to increase glucose transport in injured skeletal muscle cells.
Based on these findings, GP can ameliorate injury from muscle contractions by increasing glucose consumption via the AMPK and PI3K/Akt signaling pathways. In addition, AMPK can trigger autophagy through various mechanisms such as the ULK1-mTOR signaling pathway. Further investigation of the effects of GP on autophagy will aid in providing an understanding of its protective effects on injured skeletal muscle cells.

To the best of our knowledge, this provides mechanistic insights into the protective effects on muscle atrophy from GC-induced atrophy in muscle myotubes. The results demonstrate that GP facilitates recovery from high-dose DEXinduced muscle atrophy through the activation of glucose consumption in vitro. Confirmation of these results by in vivo studies is needed.

\section{Data Availability}

The data used to support the findings of this study are available from the corresponding author upon request.

\section{Conflicts of Interest}

The authors declared that they have no conflicts of interest.

\section{Authors' Contributions}

Rui Jiang and Manying Wang contributed equally to this work.

\section{Acknowledgments}

This work was supported by the Science and Technology Development Plan Project of Jilin Province (no. 20190101010JH), the National Key Research and Development Program of China (no. 2017YFC1702103), the Science and Technology Development Plan of Jilin Province, China (nos. 20160307027YY, 20180201075YY, and 20180101128JC), the Development and Reform commission project of Jilin Province, China (no. 2017C043), the Science and Technology Project of Jilin Province, China (no. JJKH20180378KJ), the Science and Technology Development Plan of Jilin City, China (no. 201731200), and the Science and Technology Development Plan of Changchun City (no. 18YJ013). The authors thank LetPub (http://www.letpub.com) for their linguistic assistance during the preparation of this manuscript.

\section{References}

[1] T. H. Ottens, M. Nijsten, J. Hofland et al., "Effect of highdose dexamethasone on perioperative lactate levels and glucose control: a randomized controlled trial," Critical Care, vol. 19, no. 1, p. 41, 2015.

[2] L. Feng, X. Liu, F. Cao et al., "Anti-stress effects of ginseng total saponins on hindlimb-unloaded rats assessed by a metabolomics study," Journal of Ethnopharmacology, vol. 188, pp. 39-47, 2016. 
[3] Y. Wang, Y. Chen, H. Xu, H. Luo, and R. Jiang, "Analgesic effects of glycoproteins from Panax ginseng root in mice," Journal of Ethnopharmacology, vol. 148, no. 3, pp. 946-950, 2013.

[4] H. Gong, L. Liu, C. X. Ni et al., "Dexamethasone rapidly inhibits glucose uptake via non-genomic mechanisms in contracting myotubes," Archives of Biochemistry and Biophysics, vol. 603, pp. 102-109, 2016.

[5] A. M. Pasieka and A. Rafacho, "Impact of glucocorticoid excess on glucose tolerance: Clinical and preclinical evidence," Metabolites, vol. 6, no. 3, 2016.

[6] R. M. Pereira and J. Freire de Carvalho, "Glucocorticoidinduced myopathy," Joint Bone Spine, vol. 78, no. 1, pp. 41-44, 2011.

[7] T. Kuo, C. A. Harris, and J. Wang, "Metabolic functions of glucocorticoid receptor in skeletal muscle," Molecular and Cellular Endocrinology, vol. 380, no. 1-2, pp. 79-88, 2013.

[8] A. Ochi, T. Abe, R. Nakao et al., "N-myristoylated ubiquitin ligase Cbl-b inhibitor prevents on glucocorticoid-induced atrophy in mouse skeletal muscle," Archives of Biochemistry and Biophysics, vol. 570, pp. 23-31, 2015.

[9] E. J. Kurth-Kraczek, M. F. Hirshman, L. J. Goodyear, and W. W. Winder, " 5 ' AMP-activated protein kinase activation causes GLUT4 translocation in skeletal muscle," Diabetes, vol. 48, no. 8, pp. 1667-1671, 1999.

[10] E. A. Richter and M. Hargreaves, "Exercise, GLUT4, and skeletal muscle glucose uptake," Physiological Reviews, vol. 93, no. 3, pp. 993-1017, 2013.

[11] F. S. Thong, C. B. Dugani, and A. Klip, "Turning signals on and off: GLUT4 traffic in the insulin-signaling highway," Physiology Journal, vol. 20, no. 4, pp. 271-284, 2005.

[12] R. W. Jackman and S. C. Kandarian, "The molecular basis of skeletal muscle atrophy," American Journal of Physiology-Cell Physiology, vol. 287, no. 4, pp. C834-C843, 2004.

[13] G. Go, S. Lee, A. Jo et al., "Ginsenoside Rg1 from Panax ginseng enhances myoblast differentiation and myotube growth," Journal of Ginseng Research, vol. 41, no. 4, pp. 608-614, 2017.

[14] S. Burattini, R. Ferri, M. Battistelli, R. Curci, F. Luchetti, and E. Falcieri, "C2C12 murine myoblasts as a model of skeletal muscle development: morpho-functional characterization," European Journal of Histochemistry, vol. 48, no. 3, pp. 223-233, 2004.

[15] T. Gwag, K. Park, E. Kim et al., "Inhibition of C2C12 myotube atrophy by a novel HSP70 inducer, celastrol, via activation of Akt1 and ERK1/2 pathways," Archives of Biochemistry and Biophysics, vol. 537, no. 1, pp. 21-30, 2013.

[16] M. Menconi, P. Gonnella, V. Petkova, S. Lecker, and P. Hasselgren, "Dexamethasone and corticosterone induce similar, but not identical, muscle wasting responses in cultured L6 and C2C12 myotubes," Journal of Cellular Biochemistry, vol. 105, no. 2, pp. 353-364, 2008.

[17] B. Ma, W. L. Kan, H. Zhu, S. Li, and G. Lin, "Sulfur fumigation reducing systemic exposure of ginsenosides and weakening immunomodulatory activity of ginseng," Journal of Ethnopharmacology, vol. 195, pp. 222-230, 2017.

[18] Y. Seo, M. Shon, R. Kong et al., "Black ginseng extract exerts anti-hyperglycemic effect via modulation of glucose metabolism in liver and muscle," Journal of Ethnopharmacology, vol. 190, pp. 231-240, 2016.

[19] Y. L. Ma, Y.Z. Sun, and H. H. Yang, "Protective effect of RenShen compound and DanHuang compound on muscle atrophy in suspended rats," Space Medicine \& Medical Engineering, vol. 12, no. 4, pp. 281-283, 1999.
[20] Y. Takamura, M. Nomura, A. Uchiyama, and S. Fujita, "Effects of aerobic exercise combined with panaxatriol derived from ginseng on insulin resistance and skeletal muscle mass in type 2 diabetic mice," Journal of Nutritional Science and Vitaminology, vol. 63, no. 5, pp. 339-348, 2017.

[21] F. Li, X. Li, X. Peng et al., "Ginsenoside Rgl prevents starvation-induced muscle protein degradation via regulation of AKT/mTOR/FoxO signaling in C2C12 myotubes," Experimental and Therapeutic Medicine, vol. 14, no. 2, pp. 1241-1247, 2017.

[22] O. Kang, M. Shon, R. Kong et al., "Anti-diabetic effect of black ginseng extract by augmentation of AMPK protein activity and upregulation of GLUT2 and GLUT4 expression in $\mathrm{db} / \mathrm{db}$ mice," BMC Complementary and Alternative Medicine, vol. 17, no. 1, article no. 341, 2017.

[23] C. Hsiao, Y. Hsu, Y. Tung, M. Lee, C. Huang, and C. C. Hsieh, "Effects of Antrodia camphorata and Panax ginseng supplementation on anti-fatigue properties in mice," Journal of Veterinary Medical Science, vol. 80, no. 2, pp. 284-291, 2018.

[24] X. Chen, M. Wang, X. Xu et al., "Panax ginseng total protein promotes proliferation and secretion of collagen in NIH/3T3 cells by activating extracellular signal-related kinase pathway," Journal of Ginseng Research, vol. 41, no. 3, pp. 411-418, 2017.

[25] R. Jiang, L. Sun, Y. Wang et al., "Chemical composition, and cytotoxic, antioxidant and antibacterial activities of the essential oil from ginseng leaves," Natural Product Communications (NPC), vol. 9, no. 6, pp. 865-868, 2014.

[26] Z. Xu, S. Lin, W. Wu et al., "Ghrelin prevents doxorubicininduced cardiotoxicity through TNF-alpha/NF- $\kappa$ B pathways and mitochondrial protective mechanisms," Toxicology, vol. 247, no. 2-3, pp. 133-138, 2008.

[27] W.-C. Chen, S.-R. Hsieh, C.-H. Chiu, B.-D. Hsu, and Y.-M. Liou, "Molecular identification for epigallocatechin-3-gallatemediated antioxidant intervention on the $\mathrm{H}_{2} \mathrm{O}_{2}$-induced oxidative stress in $\mathrm{H} 9 \mathrm{c} 2$ rat cardiomyoblasts," Journal of Biomedical Science, vol. 21, no. 1, article 56, 2014.

[28] S. Choi, B. Cha, B. Choi et al., "Fargesin, a component of Flos Magnoliae, stimulates glucose uptake in L6 myotubes," Journal of Natural Medicines, vol. 67, no. 2, pp. 320-326, 2013.

[29] M. Wang, X. Chen, W. Jin, X. Xu, X. Li, and L. Sun, “Ginsenoside $\mathrm{Rb} 3$ exerts protective properties against cigarette smoke extractinduced cell injury by inhibiting the p38 MAPK/NF- $\kappa$ B and TGF- $\beta 1$ /VEGF pathways in fibroblasts and epithelial cells," Biomedicine \& Pharmacotherapy, vol. 108, pp. 1751-1758, 2018.

[30] Y. Zhang and O. J. Igwe, "Exogenous oxidants activate nuclear factor kappa B through Toll-like receptor 4 stimulation to maintain inflammatory phenotype in macrophage," Biochemical Pharmacology, vol. 147, pp. 104-118, 2018.

[31] D. Meley, C. Bauvy, J. H. P. M. Houben-Weerts et al., "AMPactivated protein kinase and the regulation of autophagic proteolysis," The Journal of Biological Chemistry, vol. 281, no. 46, pp. 34870-34879, 2006.

[32] N. Shimizu, N. Yoshikawa, N. Ito et al., "Crosstalk between glucocorticoid receptor and nutritional sensor mTOR in skeletal muscle," Cell Metabolism, vol. 13, no. 2, pp. 170-182, 2011.

[33] J. W. Kim, S.-K. Ku, M. H. Han et al., "The administration of Fructus Schisandrae attenuates dexamethasone-induced muscle atrophy in mice," International Journal of Molecular Medicine, vol. 36, no. 1, pp. 29-42, 2015. 
[34] Y. H. Son, E. J. Jang, Y. W. Kim, and J. Lee, "Sulforaphane prevents dexamethasone-induced muscle atrophy via regulation of the Akt/Foxol axis in C2C12 myotubes," Biomedicine \& Pharmacotherapy, vol. 95, pp. 1486-1492, 2017.

[35] N. T. Theilen, G. H. Kunkel, and S. C. Tyagi, "The role of exercise and TFAM in preventing skeletal muscle atrophy, Journal of Cellular Physiology, vol. 232, no. 9, pp. 2348-2358, 2017.

[36] N. Ørtenblad, H. Westerblad, and J. Nielsen, "Muscle glycogen stores and fatigue," The Journal of Physiology, vol. 591, no. 18, pp. 4405-4413, 2013.

[37] J. Qiu, K. Maekawa, Y. Kitamura et al., "Stimulation of glucose uptake by theasinensins through the AMP-activated protein kinase pathway in rat skeletal muscle cells," Biochemical Pharmacology, vol. 87, no. 2, pp. 344-351, 2014.

[38] D. G. Hardie, F. A. Ross, and S. A. Hawley, "AMPK: a nutrient and energy sensor that maintains energy homeostasis," Nature Reviews Molecular Cell Biology, vol. 13, no. 4, pp. 251-262, 2012. 


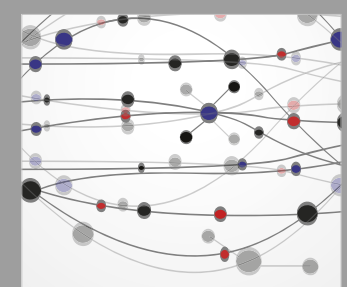

The Scientific World Journal
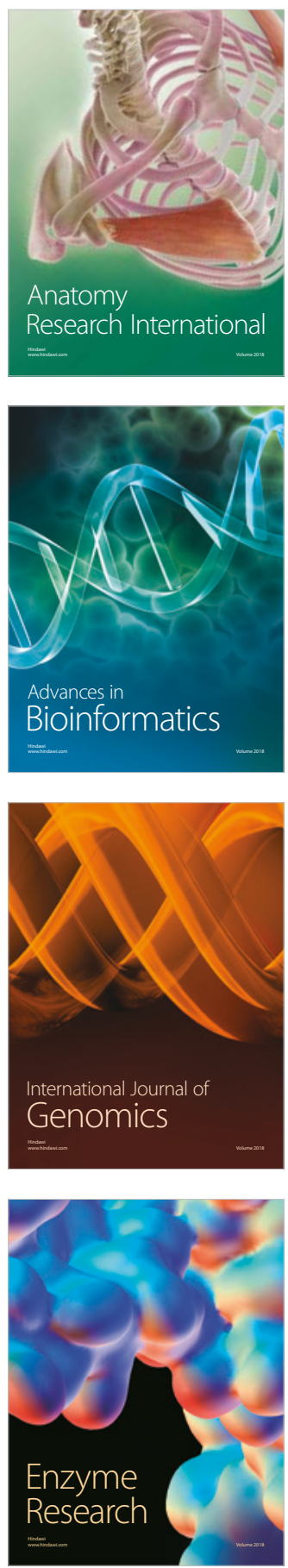
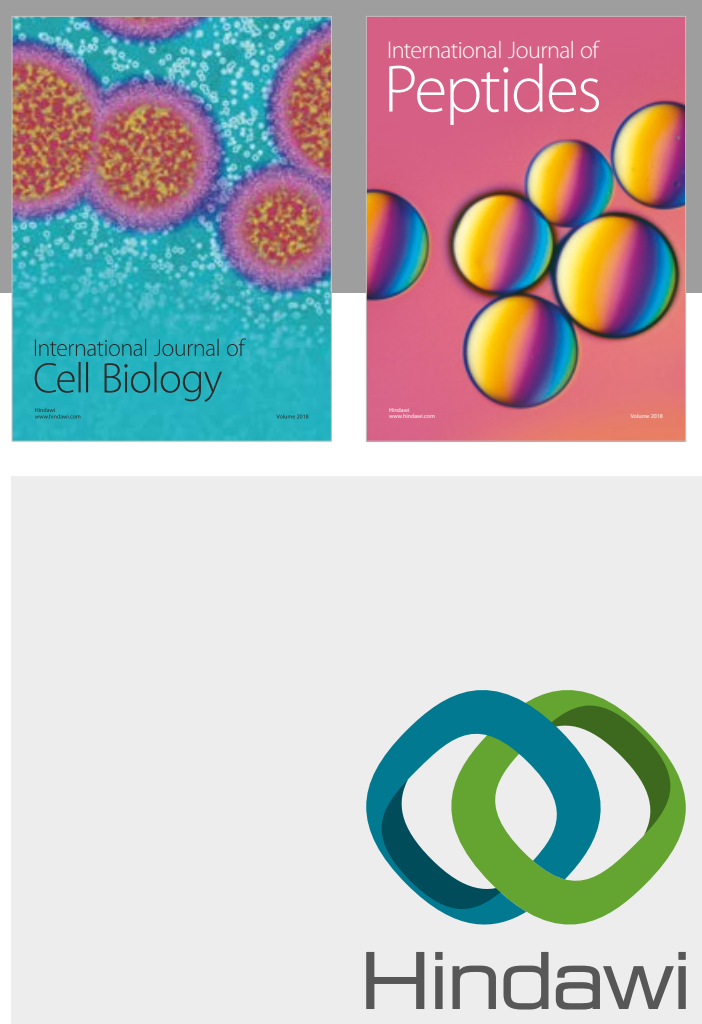

Submit your manuscripts at

www.hindawi.com
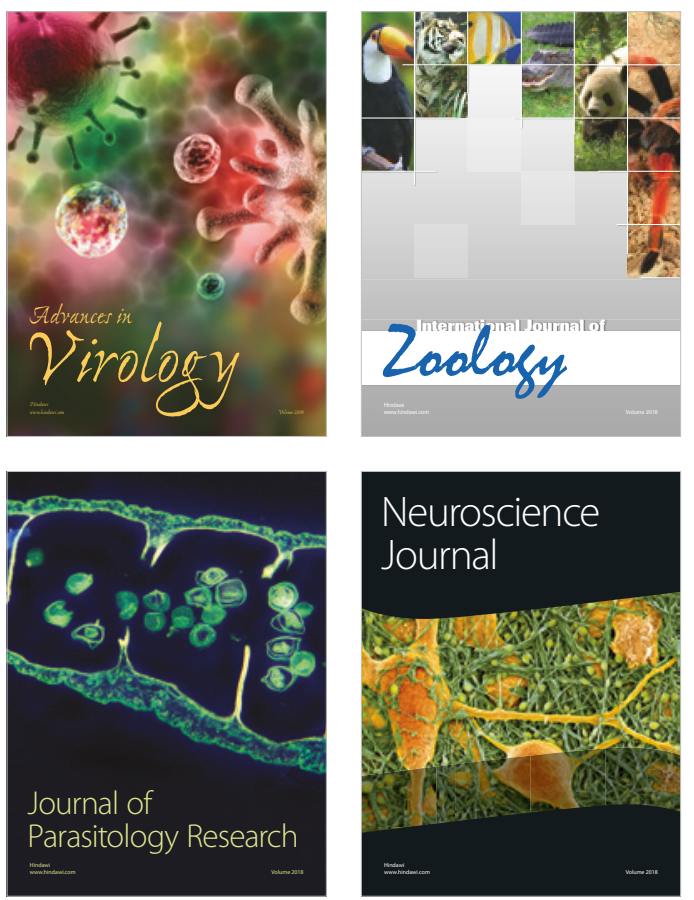
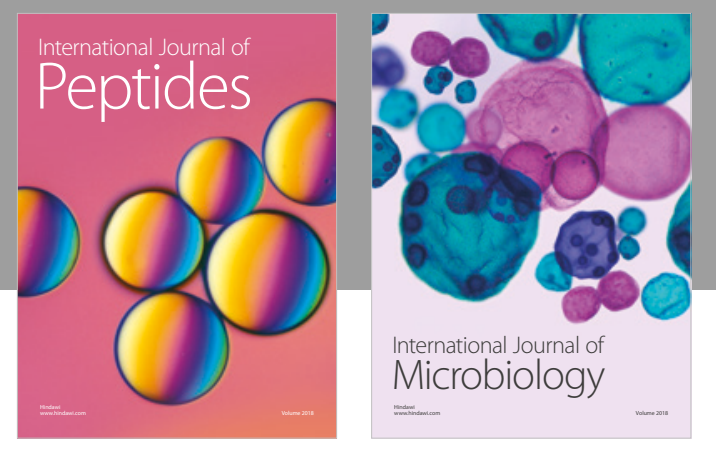

nternational Journal of Microbiology
Journal of
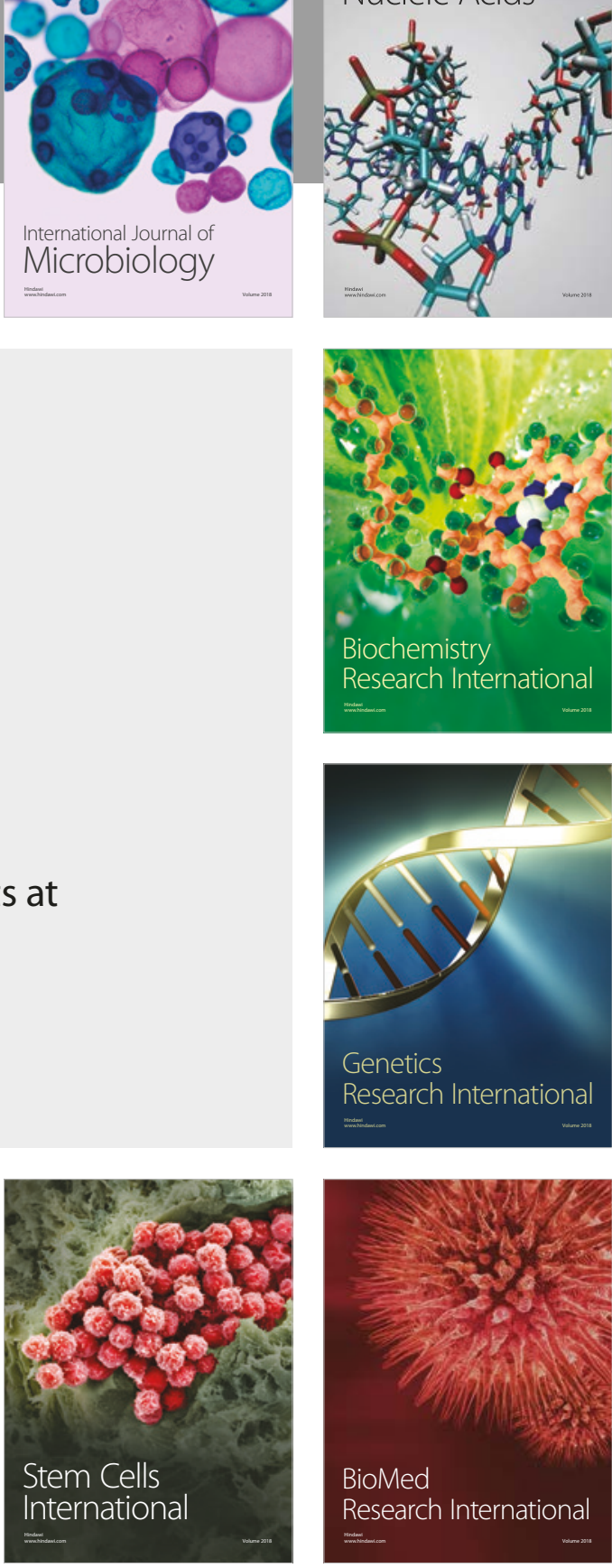
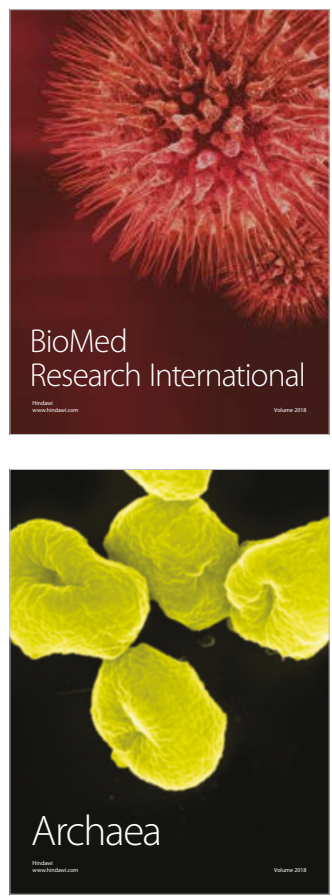